\title{
La certificación en el Instituto Nacional de Neurología y Neurocirugía Certification in the National Institute of Neurology and Neurosurgery
}

$\mathrm{R}$ ealizar trabajo en equipo es la clave para generar un ambiente de calidad en el Instituto Nacional de Neurología y Neurocirugía, con acciones responsables a través de la implantación de un sistema de seguridad y de una excelente atención; así se plasma la política de calidad que cada uno de sus integrantes brinda, al implantar un sistema de seguridad y una excelente atención, formación e investigación. Las ventajas que se deben cumplir en el INNN durante este proceso son:

Demostrar que se cumplen estándares que tienen como referencia la seguridad de los pacientes, la calidad de la atención médica, la seguridad hospitalaria, la normatividad vigente (exceptuando aquélla referente a las finanzas) y las políticas nacionales prioritarias en salud.

Evidenciar el compromiso con la mejora continua que se tiene con el paciente, su familia, el personal de la Unidad y la sociedad.
Reforzar la imagen institucional, ya que la certificación, al ser una evaluación externa, demuestra a los pacientes, familiares y a la ciudadanía, que su organización trabaja con estándares de la más alta calidad.

Probar que el INNN es competitivo internacionalmente.

Obtener la certificación implica que se cumple con las mejores prácticas y la aplicación de indicadores, estándares y métodos de evaluación de la calidad de los servicios de salud.

"El éxito se alcanza convirtiendo cada paso en una meta y cada meta en un paso".

C.C.Cortez

Ma. Guadalupe Nava Galán 